\title{
Guerra e paz: a crítica literária na imprensa brasileira
}

Manuel da Costa Pinto* 
R efletir sobre a crítica literária praticada hoje nos periódicos brasileiros equivale a fazer a arqueologia de uma guerra travada por dois grupos intelectuais que, por força de suas antipatias recíprocas, acabaram por esboçar retratos que beiram a caricatura: de um lado, acadêmicos munidos dos recursos da teoria literária e de um sofisticado aparato conceitual que freqüentemente se sobrepõe ao próprio objeto de estudo; de outro, jornalistas e colunistas das editorias de cultura dos jornais e revistas, que recusam a "obscuridade" de conceitos estéticolingüísticos e apostam no acesso direto à experiência literária que Ihes seria franqueada por uma linguagem intuitiva, fiel àquele leitor comum que todo escritor, supostamente, deseja atingir.

Essa descrição pode parecer estranha para quem abre os cadernos de cultura de nossos jornais, como o tablóide "Mais!", da Folha de S. Paulo, o suplemento "Cultura", de O Estado de S.Paulo, os cadernos "Prosa e Verso", de O Globo, e "I déias", do J ornal do Brasil - para ficarmos nos casos de jornais de abrangência nacional, lidos nos fins-de-semana em outros estados do Brasil, muitas vezes por causa desses encartes (o que acaba por referendar o fato - por si só problemático - de que o eixo Rio-São Paulo ainda se impõe como referência ao resto do país) . 0 leitor desses suplementos encontra ali uma predominância quase absoluta de textos críticos e ensaios de acadêmicos (professores universitários, mestres, doutores ou pós-graduandos), em detrimento das resenhas escritas por jornalistas e dos hoje desaparecidos "rodapés literários", outrora assinados por humanistas desvinculados de instituições de ensino superior ou pelos colunistas dos jornais.

Esse convívio aparentemente pacífico entre jornalistas e acadêmicos sugere uma capitulação da imprensa especializada diante da hegemonia da produção 
científica dos departamentos de letras, filosofia, sociologia e história de nossas universidades - e essa idéia não estará totalmente equivocada se considerarmos, por exemplo, que um jornal como a Folha de S. Paulo dá preferência, nos processos seletivos de redatores e repórteres para os cadernos "Mais!" e "Ilustrada", a candidatos que tenham ou estejam fazendo pós-graduação, conforme explicitam as normas dos concursos abertos para esses cargos.

Entretanto, volta e meia surgem vozes impacientes com tal estado de coisas, vozes cujo destempero mal contido deixa entrever que o armistício entre jornalistas e acadêmicos na verdade esconde uma situação beligerante. O exemplo mais recente é o da revista Bravo!. Criada no final de 1997, a Bravo! logo alcançou o status de mais importante revista brasileira de cultura, abrangendo, além da literatura, as artes plásticas, o teatro, o cinema, a dança e a música - sempre com grande competência na cobertura jornalística (a revista é mensal, mas consegue competir em atualidade com os jornais diários) e com um projeto visual de qualidade inaudita no cenário editorial brasileiro.

Mas, paralelamente - e é isso que importa aqui -, o corpo editorial da Bravo! se constituiu a partir de uma série de colaboradores fixos que se colocam explicitamente na contramão da tendência academicizante da imprensa cultural. Os dois porta-estandartes dessa cruzada são o poeta Bruno Tolentino e o filósofo Olavo de Carvalho (autor de um livro intitulado O imbecil coletivo, espécie de libelo anárquico contra o saber institucionalizado que tem na Universidade de São Paulo um de seus alvos prediletos). Agindo e escrevendo de um modo quase histriônico - que certamente fere o decoro universitário, mas ao qual não se pode negar uma saudável dose de bom humor, embora freqüentemente resvalando para a grosseria e o cabotinismo -, eles são levados pouco a sério pelo establishment acadêmico, que também vê a revista como um suporte luxuoso para o mainstream da indústria da alta cultura. (A expressão "indústria da alta cultura" parece um oxímoro, já que nos habituamos a considerar a indústria cultural como um fenômeno de massa, mas a Bravo! parece de fato consagrar - o que não deixa de ser pioneiro - uma esfera do consumo de elites urbanas que são tão exigentes em relação à qualidade quanto refratárias àquilo que escape ao recorte preciso, e conservador, de obras e autores canonizados - muitos deles, como J oyce ou Brecht, lidos segundo uma perspectiva pacificadora, que conjuga sua subversão no pretérito de modo a historicizá-la, tornando-os palatáveis ao presente.) Tanto é verdade que esses autores são levados pouco à sério que, num episódio emblemático, o filósofo Oswaldo Porchat, atacado por Olavo de Carvalho nas páginas de Bravo! (no artigo “O mea culpa do uspiano", seção “E nsaio!”, edição de junho de 1998), preferiu responder às críticas na seção "Tendências/D ebates" da Folha de S. Paulo, numa clara manifestação de desdém pelo interlocutor e pela própria revista. 
Mas seria justo que nós ignorássemos um veículo - um veículo que afinal conquistou seu espaço entre o público - simplesmente por que ele não tem o aval da intelligentsia universitária? Não seria essa uma forma um pouco perversa de nos furtarmos ao diálogo (de resto, recusa que repousa sobre uma tautologia: "não aceitamos as críticas dos colunistas da revista Bravo! ao saber universitário por que a revista não obedece aos protocolos do saber universitário...") ?

Insisto no caso da Bravo! porque ela me parece explicitar - de maneira algo espalhafatosa, é verdade - um conflito que permanece latente em toda a imprensa cultural brasileira. O exemplo mais candente desse conflito foi a edição de maio de 1998, em que a revista convidou diferentes autores a escreverem sobre os setenta anos do Manifesto Antropófago de O swald de Andrade. Sintomaticamente, os únicos artigos claramente simpáticos ao legado da antropofagia oswaldiana eram de dois acadêmicos: o historiador Nicolau Sevcenko ("Oswald de Andrade se tornou o vértice da renovação estética do país", diz ali Sevcenko) e o filósofo B enedito Nunes. No outro lado do ringue, jornalistas, críticos e intelectuais (entre eles o poeta Ferreira Gullar), todos mais ou menos críticos em relação ao movimento do antropófago e capitaneados por Bruno Tolentino - para quem "a 'poética modernista' foi o subproduto de subpoetas, uma receita de 'liberdade' que se resumia à incompetência formal mais libertária e culmina hoje num relaxamento idiomático de cunho improvisatório, sob selo e sanção (beli eve it or not!) universitário. [...] O vale-tudo instaurado em 22 e, sob a pétrea égide dos empreiteiros culturais da USP, alastrado à totalidade de nossa academia tornou-se pro domo sua uma aberração institucional, tão ruidosa quanto oca e autoritária". A capa da revista não deixava dúvidas quanto ao lado para o qual pendiam seus editores: uma foto de Oswald de Andrade na qual fora atirado um tomate e, sobre essa montagem, a manchete "70 Anos de Equívoco".

Com isso, desenham-se de modo mais nítido as raízes daquele cenário de guerra entre acadêmicos e jornalistas que tracei inicialmente: os críticos atuantes nas universidades, preocupados com a sistematização "científica" dos conceitos de linguagem literária e com a renovação de seus instrumentos teóricos, estariam ecoando, no âmbito da reflexão, o projeto modernista de renovação da linguagem poética; em contrapartida, críticos desvinculados de instituições acadêmicas e nostálgicos da figura do jornalista polígrafo, do humanista intuitivo, do livre-pensador que atua em várias frentes da atividade intelectual, formariam barricadas contra a crescente especialização dos saberes que, do interior da universidade, procuram recompor, no plano da teoria, a fragmentação, a complexidade e o hermetismo da proposta estética do modernismo de 22 - que assim passa a ser visto como matriz geradora da bête noire representada pelas diversas correntes da teoria literária. 
O grande marco dessa polarização foi o surgimento do grupo Clima, formado nos anos 40 por um núcleo inicial composto por Antonio Candido, Décio de Almeida Prado, Paulo E mílio Salles G omes e L ourival Gomes M achado ( um estudo detalhado da trajetória desse círculo de intelectuais está no livro Destinos Mistos - Os críticos do Grupo Clima em São Paulo (1940-1968), de Heloisa Pontes, publicado pela editora Companhia das Letras, ao qual devo a essência dos tópicos discutidos a seguir neste artigo). Até então, a crítica literária brasileira se dava preferencialmente nos "rodapés" - espaços semanais reservados ao comentário de livros e acontecimentos da vida literária. Normalmente caracterizados pelo tom informal, pelas digressões de ordem pessoal, cotidiana, e pela percepção impressionista da obra poética ou ficcional, os rodapés eram geralmente assinados por intelectuais de formação pluralista e que atuavam em diferentes contextos; eram jornalistas, escritores, críticos de artes plásticas ou advogados cuja educação tivera como base a leitura dos grandes romances da literatura ocidental e que por isso estavam aptos a discutir o momento literário com uma erudição que, todavia, não os tornava especi alistas no sentido que a divisão dos departamentos universitários viria a dar ao termo.

O bviamente, não se pode confundir a crítica subjetiva, que em larga medida se pratica ainda hoje nos jornais brasileiros de pequeno porte, com a atividade de autores cujo rigor se constituía a partir de um repertório muito pessoal - mas profundamente erudito - de referências bibliográficas. Como observa H eloisa Pontes, críticos como Álvaro Lins (que assinava no Correio da Manhã o mais importante rodapé da imprensa brasileira), Sérgio Milliet, Afrânio Coutinho, Sérgio B uarque de Holanda e Otto M aria Carpeaux - todos colaboradores dos principais jornais brasileiros - inscrevem-se na "tentativa de dotar os estudos literários de instrumentos analíticos mais poderosos - construídos na intersecção e no diálogo com as ciências do social -, tendo em vista a superação do impressionismo e do amadorismo que ainda caracterizavam a crítica da época" (op.cit., p. 101).

Entretanto, a construção da figura do crítico como intérprete privilegiado da obra literária ainda não redundara na constituição de uma disciplina exclusivamente vocacionada para o estudo do objeto "literatura" dentro de uma esfera autônoma. A mirada sociológica de Sérgio Buarque de $\mathrm{H}$ olanda ou o assombroso enciclopedismo de Carpeaux, por exemplo, são ainda parte de abordagens intransferíveis, um compósito heterogêneo de fontes e autores que não pertencem a um mesmo cânone e que só se harmonizam dentro da obra personalíssima desses dois humanistas.

Nesse sentido, o lançamento da revista Clima, em 1941, simultaneamente inaugura um novo tipo de jornalismo cultural e aponta para a consolidação de uma abordagem "científica" da obra literária que logo iria tomar conta das univer- 
sidades. Composto por D écio de Almeida Prado, Lourival Gomes M achado, Paulo E milio Salles Gomes, Ruy Coelho, Antonio Candido de Mello e Souza e Gilda de M oraes R ocha (hoje Gilda de M ello e Souza, sua esposa), o grupo Clima trazia a marca de uma divisão de trabalho que já apontava para a especialização característica da formação universitária. Foi nas reuniões para a criação da revista Clima que se decidiu que a seção de literatura caberia a Antonio Candido, a de cinema a Paulo E mílio Salles G omes, a de artes plásticas a Lourival Gomes M achado e a de crítica teatral a Décio de Almeida Prado - o que de certa forma selou o destino de cada um desses autores, que a partir daí definiriam sua área de atuação predominante.

Crítico literário "oficial” de Clima, Antonio Candido faria uma opção definitiva pelo ensino de literatura a partir do fim dos anos 50, em detrimento da crítica militante e do jornalismo cultural. Contratado em dezembro de 1960 pela USP para criar a disciplina de teoria literária, Antonio Candido assumiu a tarefa de constituir um corpo docente e um espaço de discussão teórica sem precedentes na universidade brasileira - fato que viria a se repetir na Unicamp, quando coordenou entre 1976 e 1978 o Instituto de Estudos da Linguagem.

Entretanto, não se pode esquecer o papel do "jornalismo cultural" em sua biografia intelectual: autor de rodapés intitulados "Notas de crítica literária" na Folha da Manhã e no Diári o de São Paulo, Antonio Candido seria ainda responsável, em 1956, pelo projeto do "Suplemento Literário" de O Estado de S. Paulo, que seria o mais importante caderno de cultura da imprensa brasileira.

O “Suplemento L iterário" teve Décio de A Imeida Prado como editor até 1967. A essa altura, porém, o trânsito de mão dupla entre universidade e jornalismo cultural já havia se consolidado. Do ponto de vista acadêmico, o resultado da atividade de Antonio Candido foi a presença das mais diversas vertentes da crítica contemporânea na universidade. É preciso lembrar que ele teve, entre seus orientandos ou discípulos, intelectuais de feições tão distintas quanto J oão Alexandre B arbosa, Davi Arrigucci J r., H aroldo de Campos, Décio Pignatari, L uiz Costa Lima, Boris Schnaiderman ou Roberto Schwarz - ainda que, em alguns casos, Antonio Candido tenha sido apenas um orientador "formal", não participando de pesquisas que, todavia, muitas vezes tornou possíveis apenas por sua presença institucional em momentos politicamente delicados (é esse sobretudo o caso de Luiz Costa Lima).

Olhando as coisas do ponto de vista da crítica literária praticada na imprensa, a lista acima traz os nomes de alguns dos autores mais presentes hoje em nossos cadernos de cultura desde os anos 70 - seja como autores de ensaios, seja como entrevistados, seja como autores de livros que são ali resenhados, seja (de forma mais indireta) como orientadores de pós-graduandos que freqüentemente 
são convidados a colaborar nos periódicos culturais, todos trazendo para a ordem do dia o dialeto particular de escolas de interpretação literária como o estruturalismo, a sociologia da arte, o desconstrucionismo ou a estética da recepção.

Essa consolidação da presença acadêmica na imprensa cultural poderia ser constatada ainda nos diversos cadernos literários que surgiram nos últimos vinte anos, desde o "Folhetim" da Folha de S. Paulo, que seria substituído pelo caderno "Livros" ( por sua vez transformado no atual “M ais!") até os já citados suplemento "Cultura", de O Estado de S.Paulo, e os cadernos cariocas "Prosa e Verso" e "I déias", aos quais acrescentaria agora o "Caderno de F im de Semana" da Gazeta Mercantil, o tablóide "Eu \& Cultura", do jornal Valor, e o "Caderno de Sábado" do J ornal da Tarde - todos de alguma forma tributários, na forma e no conteúdo, ao "Suplemento Literário" de Antonio Candido e Décio de Almeida Prado.

$M$ ais recentemente, as leis de incentivo à cultura e a descoberta do marketing cultural fizeram crescer o interesse de editoras de pequeno e médio porte na criação de revistas literárias que ambicionam ter um desempen ho comercial satisfatório. É o caso das revistas Bravo! e Palavra (que não se restringem à literatura), Livro A berto (mais voltada para notícias do mercado editorial e breve notas sobre lançamentos de livros) e CULT - Revista Brasileira de Literatura (da qual fui o criador e sou o atual editor, não me sentindo à vontade, portanto, para fazer um juízo crítico sobre a publicação). Finalmente, a informatização do processo de edição e o decorrente barateamento dos custos de produção permitiram o surgimento de um grande número de revistas de criação literária. São revistas como Ini mi go Rumor e Ficções (ambas da editora Sette Letras), Monturo (de Santo André), Dimensão (de Uberaba) e Medusa (de Curitiba) - todas predominantemente voltadas para a publicação de textos de criação literária, mas também com espaços para a reflexão crítica. Encaixa-se nessa categoria também o Suplemento Literári o de Minas Gerais, que conta com subsídio do governo mineiro.

Em todos esses periódicos se repete, com graus diferentes de violência e passividade, o mesmo conflito: de um lado, jornalistas e editores saudosos da figura do humanista de saber enciclopédico e estilo franco atirador que, a contragosto, aceitam a colaboração de professores universitários e seus orientandos; de outro, acadêmicos e um número cada vez maior de jornalistas que cursam pósgraduação e querem dar igual peso, na edição dos periódicos, às obras de poesia e ficção e aos ensaios de teoria literária.

Ao que poderíamos atribuir essa rivalidade latente? Para além de mesquinhos interesses corporativistas, pode-se dizer que o que imanta essa radicalização de pontos de vista é, em última análise, uma forma de compreender a arte literária. Em que pesem suas diferenças recíprocas, os teóricos de escolas como o formalismo, o estruturalismo, a semiótica, o desconstrucionismo, a sociologia 
marxista, a estética da recepção etc. etc. etc. partem do pressuposto de que a linguagem não é uma forma de representação transparente da realidade, que qualquer mensagem verbal acarreta um número infinito de outras mensagens que constituem seu conteúdo e comentam en abîme seu sentido - e que, por conseguinte, a obra literária não está jamais encerrada em si mesma, mas possui, sob sua superfície sígnica, uma teoria do que é a literatura para aquele autor e para aquela obra, um conjunto de instruções textuais que nos guiam pelos labirintos de um mundo que está para além do mundo empírico, mas que mostra, no espelho da ficção, como esse mundo empírico tampouco é transparente, que a realidade objetiva também é dependente de interpretações e teorias. E m contrapartida, os defensores do antigo humanismo acreditam que essas teorias servem apenas para justificar o relativismo moral e filosófico que contraria o bom e velho senso comum, o otimismo epistemológico, a confiança nas idéias claras e distintas e a crença em verdades absolutas da ciência e da autoridade intelectual.

A partir disso, talvez seja mais fácil compreender a continuidade que existe entre os movimentos de vanguarda da primeira metade do século, com seu ímpeto iconoclasta, e a proliferação de correntes de teoria literária que tentariam explicar, para o público perplexo, a complexidade dessa realidade fragmentária que nos escapa por entre os dedos. Mas também é mais fácil compreender a angústia e a reação virulenta que essa descrição do mundo provoca em mentes nostálgicas de um mundo unitário e compreensível. Se for assim, então os conflitos anedóticos entre jornalistas e acadêmicos reproduzem, em tom menor, um conflito que perpassa a nossa modernidade. 